\title{
Effectiveness of Lanthanum Carbonate Treatment Used in Combination with Other Phosphate Binders in Peritoneal Dialysis Patients
}

\author{
Shunsuke Yamada ${ }^{1}$, Hisako Yoshida ${ }^{2}$, Masatomo Taniguchi ${ }^{1}$, Shigeru Tanaka ${ }^{1}$, \\ Masahiro Eriguchi ${ }^{1}$, Toshiaki Nakano ${ }^{1}$, Kazuhiko Tsuruya ${ }^{1,2}$ and Takanari Kitazono ${ }^{1}$
}

\begin{abstract}
Objective Phosphate binders are used in the treatment of hyperphosphatemia in peritoneal dialysis (PD) patients. An ideal phosphate binder for long-term use must be effective with little or no side effects. We evaluated the long-term efficacy and side effects of lanthanum carbonate $(\mathrm{LaC})$ used in combination with other phosphate binders in PD patients.

Patients The subjects of this retrospective study were 30 PD patients who received LaC at Kyushu University. The effect of $\mathrm{LaC}$ on various biochemical parameters (serum phosphate, calcium and parathyroid hormone), daily dose of other phosphate binders, gastrointestinal side effects, and nutritional status were determined during the 24-week treatment. We also evaluated the rate of achievement of the Japanese Society of Dialysis Treatment guidelines for secondary hyperparathyroidism and used multivariate analysis to determine the factors associated with the efficacy of LaC.

Results $\mathrm{LaC}(960 \pm 412 \mathrm{mg} /$ day) reduced serum phosphate from 6.2 to $5.3 \mathrm{mg} / \mathrm{dL}$. The rate of achievement of the guideline target improved after 24 weeks of $\mathrm{LaC}$ treatment. The dose of other phosphate binders and dialysis volume remained unchanged during the treatment. Although $53 \%$ of patients experienced at least one gastrointestinal side effect, $\mathrm{LaC}$ treatment did not affect the nutritional status, and none of the patients discontinued LaC. Multivariate analysis identified low stature, old age and high baseline total creatinine clearance as significant factors that determine the effectiveness of $\mathrm{LaC}$ in PD patients.

Conclusion Low dose $\mathrm{LaC}$ treatment used in combination with other phosphate binders improved serum phosphate control with tolerable gastrointestinal symptoms in PD patients.
\end{abstract}

Key words: hyperphosphatemia, lanthanum carbonate, nutrition, peritoneal dialysis, phosphate binder

(Intern Med 51: 2097-2104, 2012)

(DOI: 10.2169/internalmedicine.51.6814)

\section{Introduction}

Hyperphosphatemia, which is highly prevalent in both hemodialysis and PD patients, is a serious complication that can lead to secondary hyperparathyroidism (SHPT), renal osteodystrophy and vascular calcification (1-3). The control of serum phosphate $(\mathrm{Pi})$ level within the recommended range is an important therapeutic goal for better prognosis of patients on dialysis (4-6). Among the treatment modali- ties available for hyperphosphatemia, administration of $\mathrm{Pi}$ binders is the preferred therapy (7). Although several types of Pi binders are currently used clinically in PD patients, they are known to have serious side effects. For example, aluminum salts can cause bone and neurological disorders, calcium (Ca) carbonate can result in $\mathrm{Ca}$ overload and has gastrointestinal side effects, and sevelamer hydrochloride has several gastrointestinal side effects, $\mathrm{pH}$ lowering effect and high pill burden (8). Therefore, new types of Pi binders that can on one hand lower serum Pi and on the other have little

${ }^{1}$ Department of Medicine and Clinical Science, Graduate School of Medical Sciences, Kyushu University, Japan and ${ }^{2}$ Department of Integrated Therapy for Chronic Kidney Disease, Graduate School of Medical Sciences, Kyushu University, Japan

Received for publication October 26, 2011; Accepted for publication March 14, 2012

Correspondence to Dr. Kazuhiko Tsuruya, tsuruya@intmed2.med.kyushu-u.ac.jp 
or no side effects are desirable.

Lanthanum carbonate ( $\mathrm{LaC})$, an aluminum-free and $\mathrm{Ca}$ free, $\mathrm{pH}$ independent, less absorbable $\mathrm{P}$ binder, has been available in Japan since 2009 (9). LaC is less hypercalcemic and comparably tolerable compared to the conventional $\mathrm{Pi}$ binders albeit a certain percentage of hemodialysis patients develop gastrointestinal symptoms (10). To date, two clinical studies have demonstrated that LaC effectively reduces serum $\mathrm{Pi}$ and is devoid of serious side effects in $\mathrm{PD}$ patients $(11,12)$. However, the treatment duration in these two clinical studies was relatively short (8 weeks), and they only tested the efficacy of LaC monotherapy, not combination therapy with other conventional Pi binders as is the case in the clinical setting. In other words, there is no information on the efficiency and tolerability of long-term LaC therapy used alone or in combination with conventional Pi binders in PD patients.

The purpose of the present study was to determine the additive effect of $\mathrm{LaC}$ in PD patients already treated with other Pi binders. For this purpose, we retrospectively evaluated the efficacy and tolerability of 24-week treatment with $\mathrm{LaC}$ in PD patients. We also assessed the factors that influence the Pi-lowering effect of $\mathrm{LaC}$.

\section{Materials and Methods}

\section{Patients and study protocol}

The present retrospective observational study included PD patients who were treated for 24 weeks with $\mathrm{LaC}$ at Kyushu University Hospital between April 2006 and March 2011. In March 2011, 49 patients were receiving PD therapy at our hospital. Among them, 33 patients whose serum Pi control was not optimal had been treated with $\mathrm{LaC}$. We excluded patients who, within 24 weeks after the start of $\mathrm{LaC}$ underwent kidney transplantation $(n=1)$, or started cinacalcet hydrochloride therapy $(n=1)$. We also excluded patients who received the combination of hemodialysis and $\mathrm{PD}(\mathrm{n}=1)$. The remaining 30 patients were the subjects of the study. The starting dose of $\mathrm{LaC}$ ranged from 500 to $1,000 \mathrm{mg} /$ day. The dose was increased by the attending physician based on the serum Pi level measured at each regular follow-up as far as permitted by the gastrointestinal side effects. When serum Pi level decreased to less than the lower limit, the doses of Pi binders other than $\mathrm{LaC}$ were reduced. The target range was set as recommended by the Japanese Society of Dialysis Treatment (JSDT). Some of these 33 patients received LaC because they could not start or increase the dose of other Pi binders for the following reasons; some patients did not use Ca-based Pi binders for hypercalcemia, and others could not use or increase the dose of sevelamer hydrochloride due to the associated gastrointestinal side effects.

Serum $\mathrm{Pi}, \mathrm{Ca}$, and albumin were measured every 4 weeks. Whole parathyroid hormone (PTH) level was measured every 12 weeks. We determined the basal serum Pi level as calculated according to the average of serum Pi level re- corded in the last three months at the start of $\mathrm{LaC}$ treatment. The $\Delta \mathrm{Pi}$ was defined by the following equation: $\Delta \mathrm{Pi}=$ serum Pi (each week) - serum Pi (baseline average). Serum Ca refers to albumin-adjusted Ca concentration when serum albumin was below $4.0 \mathrm{~g} / \mathrm{dL}$. The present study was approved by the Ethics Committee at Kyushu University, and writteninformed consent was obtained from each patient.

\section{Rate of achievement of target rate recommended by JSDT guidelines for SHPT}

We also evaluated the rate of achievement of the target range recommended by JSDT guidelines for SHPT with regard to serum $\mathrm{Pi}(3.5 \mathrm{mg} / \mathrm{dL} \leq \mathrm{Pi} \leq 6.0 \mathrm{mg} / \mathrm{dL})$, and $\mathrm{Ca}(8.4$ $\mathrm{mg} / \mathrm{dL} \leq \mathrm{Ca} \leq 10.0 \mathrm{mg} / \mathrm{dL})$, and whole PTH $(35 \mathrm{pg} / \mathrm{mL} \leq$ whole $\mathrm{PTH} \leq 106 \mathrm{pg} / \mathrm{mL})$ (13).

\section{Assessment of LaC-related side effects}

To determine the prevalence of gastrointestinal side effects associated with $\mathrm{LaC}$, the medical records were checked for the following gastrointestinal symptoms: reflux, abdominal pain, indigestion, diarrhea and constipation.

\section{Assessment of nutritional status and adequacy of dialysis}

Nutritional status was assessed by various biochemical parameters (blood urea nitrogen, serum creatinine, total protein, albumin, total cholesterol, triglyceride, and normalized protein catabolic ratio), as well as by body weight. We also assessed the adequacy of dialysis, by dialysis volume, Kt/V urea and weekly creatinine clearance. These parameters were recorded at baseline and at week 24 .

\section{Comparison of effects of $\mathrm{LaC}$ in patients with differ- ent serum $\mathrm{Ca}$ and serum $P$ control at baseline}

To determine the effect of $\mathrm{LaC}$ in patients with different Pi control, patients were divided into two groups based on the baseline Pi level; patients with serum $\mathrm{Pi} \geq 6 \mathrm{mg} / \mathrm{dL}$ and those with serum $\mathrm{Pi}<6 \mathrm{mg} / \mathrm{dL}$. Similarly, to determine the effect of $\mathrm{LaC}$ on patients with different $\mathrm{Ca}$ control at baseline, patients were divided into two groups based on the baseline serum Ca level: $\geq 10.0 \mathrm{mg} / \mathrm{dL}$ and $<10.0 \mathrm{mg} / \mathrm{dL}$.

\section{Factors associated with the effectiveness of LaC treatment}

To assess the effectiveness of $\mathrm{LaC}$ treatment, we divided the 30 patients into two groups based on the mean $\Delta \mathrm{Pi}$ value calculated during the entire 24 weeks of treatment. The cutoff value for separating the patients into two groups was the mean $\Delta \mathrm{Pi}$, calculated by the following equation; mean $\Delta \mathrm{Pi}=(\Delta$ Piweek-4 $+\Delta$ Piweek-8 $+\Delta$ Piweek-12 + $\Delta$ Piweek-16 $+\Delta$ Piweek-24) divided by 5 . Twelve patients with $\Delta \mathrm{Pi}$ higher than the cutoff value were considered the "responders", while the remaining 18 patients with $\Delta \mathrm{Pi}$ values lower than the cutoff value were defined as "nonresponders". Multiple logistic regression analysis was used to determine the factors associated with serum Pi reduction 
Table 1. Clinical and Biochemical Parameters at Baseline $(\mathbf{n}=30)$

\begin{tabular}{|c|c|}
\hline Age, year & $50.9 \pm 10.0$ \\
\hline Sex, male $(\%)$ & $20(67)$ \\
\hline Weight, kg & $62.6 \pm 11.6$ \\
\hline Height, m & $1.65 \pm 0.10$ \\
\hline BMI, $\mathrm{kg} / \mathrm{m}^{2}$ & $23.0 \pm 3.1$ \\
\hline \multicolumn{2}{|l|}{ Underlying kidney disease } \\
\hline $\mathrm{DM}, \mathrm{n}(\%)$ & $10(33)$ \\
\hline Non-DM, n (\%) & $20(67)$ \\
\hline Time on dialysis, days & $575 \pm 312$ \\
\hline Phosphate, mg/dL & $6.2 \pm 0.7$ \\
\hline Calcium, mg/dL & $9.8 \pm 0.6$ \\
\hline Calcium phosphate product, $\mathrm{mg}^{2} / \mathrm{dL}^{2}$ & $56.9 \pm 9.1$ \\
\hline $\mathrm{ALP}, \mathrm{U} / \mathrm{L}$ & $247(173-423)$ \\
\hline Whole PTH, pg/mL & $85.4(48.3-167.8)$ \\
\hline Blood urea nitrogen, $\mathrm{mg} / \mathrm{dL}$ & $61.8 \pm 12.7$ \\
\hline Serum creatinine, $\mathrm{mg} / \mathrm{dL}$ & $12.1 \pm 2.9$ \\
\hline Total protein, $\mathrm{g} / \mathrm{dL}$ & $6.3 \pm 0.6$ \\
\hline Albumin, $\mathrm{g} / \mathrm{dL}$ & $3.5 \pm 0.5$ \\
\hline Total cholesterol, mg/dL & $144 \pm 109$ \\
\hline Triglyceride, mg/dL & $185 \pm 48$ \\
\hline \multicolumn{2}{|l|}{ Dialysis modality } \\
\hline $\operatorname{APD}(\%)$ & $20(67)$ \\
\hline CAPD $(\%)$ & $5(17)$ \\
\hline Icodextrin use, $\%$ & $23(77)$ \\
\hline \multicolumn{2}{|l|}{ Phosphate binder use } \\
\hline Calcium carbonate, $\mathrm{n}(\%)$ & $22(73)$ \\
\hline Sevelamer hydrochloride, $\mathrm{n}(\%)$ & $8(27)$ \\
\hline Both, n (\%) & $5(17)$ \\
\hline Cinacalcet hydrochloride use, $\mathrm{n}(\%)$ & $1(3)$ \\
\hline \multicolumn{2}{|c|}{$\begin{array}{l}\text { Data are mean } \pm \mathrm{SD} \text {, median (1st quartile, 3rd quartile), or } \\
\text { number (percentage). } \\
\text { BMI: body mass index, DM: diabetes mellitus, ALP: alkaline } \\
\text { phosphatase, PTH: parathyroid hormone, APD: automated } \\
\text { peritoneal dialysis, CAPD: continuous ambulatory peritoneal } \\
\text { dialysis }\end{array}$} \\
\hline
\end{tabular}

Table 2. Categorization of Serum Levels of $\mathrm{Ca}$ and Pi at Baseline Based on the Japanese Society of Dialysis Treatment Guidelines ( $\mathbf{n = 3 0})$

\begin{tabular}{lrrr}
\hline & $\mathrm{Ca}<8.4 \mathrm{mg} / \mathrm{dL}$ & $\begin{array}{c}8.4 \leq \mathrm{Ca} \leq 10.0 \\
\mathrm{mg} / \mathrm{dL}\end{array}$ & $\mathrm{Ca}>10.0 \mathrm{mg} / \mathrm{dL}$ \\
\hline $\mathrm{Pi}<3.5 \mathrm{mg} / \mathrm{dL}$ & $0(0 \%)$ & $0(0 \%)$ & $0(0 \%)$ \\
$3.5 \leq \mathrm{Pi} \leq 6.0 \mathrm{mg} / \mathrm{dL}$ & $5(17 \%)$ & $5(17 \%)$ & $3(10 \%)$ \\
$\mathrm{Pi}>6.0 \mathrm{mg} / \mathrm{dL}$ & $1(3 \%)$ & $11(36 \%)$ & $5(17 \%)$ \\
\hline Data are number (percentage) of patients. & & \\
Ca: calcium, Pi: phosphate & &
\end{tabular}

after LaC treatment in PD patients, with "responders" set as the dependent variable.

\section{Statistical analysis}

Data were expressed as mean $\pm \mathrm{SD}$, median (1st quartile, 3rd quartile), or number (percentage) unless otherwise specified. The chi-square test or unpaired $t$-test was used to compare differences between the two groups. Dunnett test was used to compare the serial changes in serum $\mathrm{Pi}$ and $\mathrm{Ca}$ after $\mathrm{LaC}$ treatment with the baseline values. Kruskal-Wallis analysis of variance was used to compare the serial changes in whole PTH. Multivariate logistic regression analysis was conducted to provide adjusted odds ratio for "responders". Variables that achieved statistical significance in univariate analysis were included in the multivariate analysis. A twotailed $\mathrm{p}$ value less than 0.05 was considered statistically significant. All statistical analyses were conducted using JMP 8.0 (SAS Institute, Tokyo, Japan).

\section{Results}

\section{Clinical characteristics}

Table 1 shows the demographic and laboratory characteristics recorded at baseline. Twenty patients were males, and 10 patients had diabetes mellitus. The time on dialysis ranged from 130 to 1,071 days, and 22 patients used automated PD systems. Serum levels of Pi, Ca, and whole PTH ranged from $6.2 \pm 0.6 \mathrm{mg} / \mathrm{dL}, 9.8 \pm 0.6 \mathrm{mg} / \mathrm{dL}$, and $48.3-167.8$ $\mathrm{pg} / \mathrm{mL}$, respectively. The results of categorization of serum $\mathrm{Ca}$ and Pi levels at baseline are shown in Table 2. At baseline, $14 \%$ of the patients achieved the target range of serum $\mathrm{Ca}$ and $\mathrm{Pi}$. Seventy-three percent of the patients used $\mathrm{Ca}$ carbonate alone, while $27 \%$ used sevelamer hydrochloride. In the single patient who used cinacalcet hydrochloride at baseline, the dose did not change during the 24-week period. None of the patients discontinued $\mathrm{LaC}$ during the 24week period.

\section{Serial changes in biochemical parameters}

Figure 1 shows the serial changes in serum $\mathrm{Pi}$, and $\Delta \mathrm{Pi}$, $\mathrm{Ca}$, and whole PTH. Compared to the baseline, serum Pi and $\triangle \mathrm{Pi}$ significantly decreased at 8 weeks after $\mathrm{LaC}$ treatment. In contrast, serum levels of $\mathrm{Ca}$ and whole PTH did not change during the study period.

\section{Rate of achievement of JSDT guidelines for each biochemical parameter}

Table 3 also lists the serial changes in the rate of achievement of JSDT guidelines for SHPT in each biochemical parameter. The rate of achievement of serum Pi following the use of $\mathrm{LaC}$ was higher at the end of the study period $(93 \%)$ than at baseline (43\%), while that for $\mathrm{Ca}$ and whole PTH did not change during the 24 weeks.

\section{Serial changes in daily doses of Pi binders}

The mean daily doses of Ca carbonate and sevelamer hydrochloride remained the same during the study period $(\mathrm{Ca}$

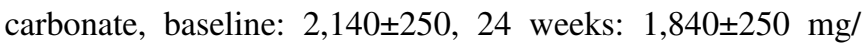

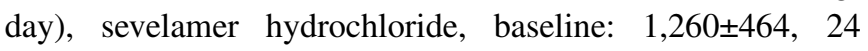
weeks: $1,380 \pm 466 \mathrm{mg} /$ day). The mean dose of $\mathrm{LaC}$ also remained unchanged during the study period [baseline: 930 \pm 497 (range, 750-1,500), 24 weeks: 960 \pm 412 (range, 7502,250) $\mathrm{mg} /$ day] (Fig. 2).

\section{LaC-induced gastrointestinal symptoms}

Table 4 lists the percentage of patients who developed 
A

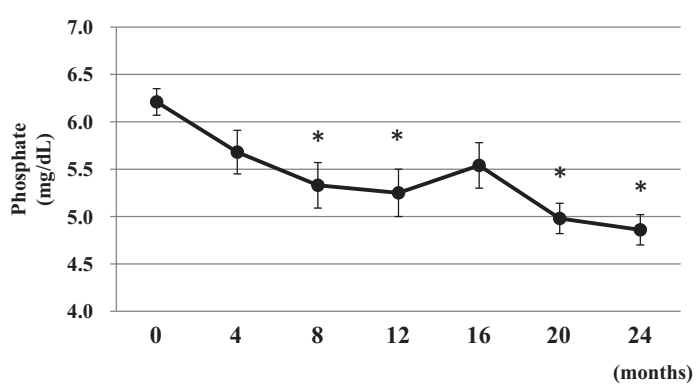

C

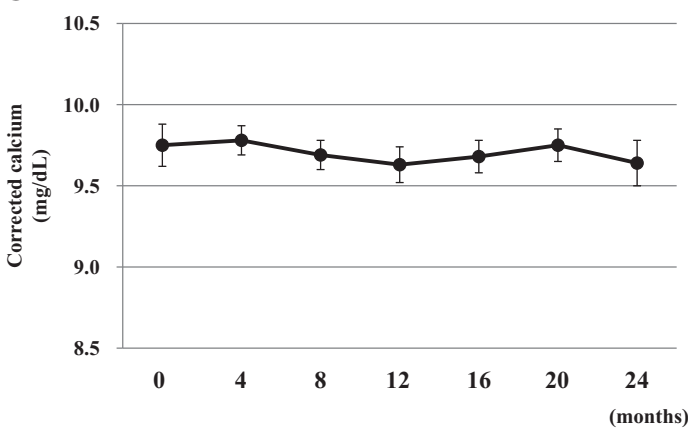

B

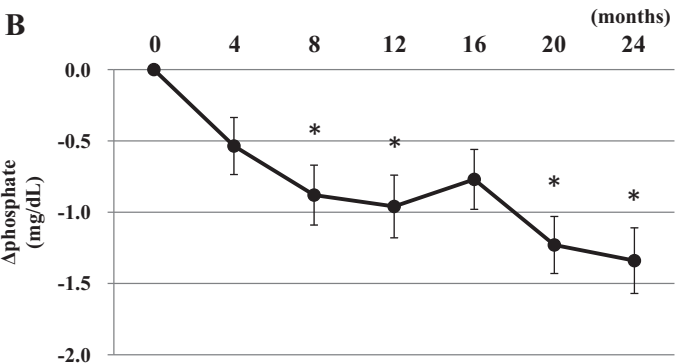

D

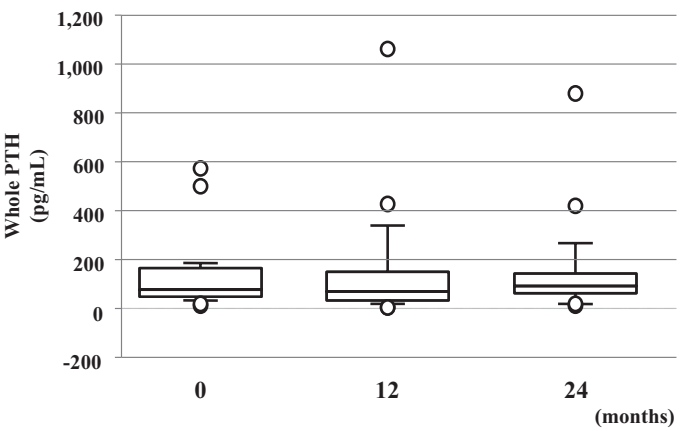

Figure 1. Serial changes in various biochemical parameters after commencement of lanthanum carbonate therapy. Serum phosphate (Pi) (A), serum $\Delta \mathrm{Pi}(\mathrm{B})$, serum corrected calcium (C), and serum whole parathyroid hormone (PTH) (D) are shown. Serum $\Delta \mathrm{Pi}$ is defined as follows; serum $\Delta \mathrm{Pi}$ = serum Pi (each week) - serum Pi (week 0). Serum levels of Pi and calcium at each week are compared to baseline value by Dunnett test. Serum whole PTH at each time point is compared to baseline value by Kruskal-Wallis analysis of variance. Data in (A), (B), and (C) are mean \pm SEM. Data in (D) are box-and-whisker plots. In these plots, lines within the boxes represent median values; the upper and lower lines of the boxes represent the 25 th and 75 th percentiles, respectively; and the upper and lower bars outside the boxes represent the 90th and 10th percentiles, respectively. $*$ p $<0.05$ versus serum $P i$ at 0 week.

Table 3. Serial Changes in the Rate of Achievement of the Japanese Society of Dialysis Treatment Guidelines in 30 Patients who Received 24-week Lanthanum Carbonate Treatment

\begin{tabular}{lrrrrrrr}
\hline & week 0 & week 4 & week 8 & week 12 & week 16 & week 20 & week 24 \\
\hline $8.4 \leq \mathrm{Ca} \leq 10.0 \mathrm{mg} / \mathrm{dL}$ & $73 \%$ & $67 \%$ & $73 \%$ & $80 \%$ & $83 \%$ & $73 \%$ & $67 \%$ \\
$3.5 \leq \mathrm{Pi} \leq 6.0 \mathrm{mg} / \mathrm{dL}$ & $43 \%$ & $73 \%$ & $73 \%$ & $77 \%$ & $70 \%$ & $80 \%$ & $93 \%$ \\
$35 \leq$ whole $\mathrm{PTH} \leq 106 \mathrm{pg} / \mathrm{mL}$ & $73 \%$ & no data & no data & $73 \%$ & no data & no data & $70 \%$ \\
\hline
\end{tabular}

Data are percentages of the patients who achieved the target range of each biochemical parameter.

Ca: calcium, Pi: phosphate, PTH: parathyroid hormone

gastrointestinal symptoms after commencement of $\mathrm{LaC}$ treatment based on analysis of the medical records. Of the 30 patients treated with $\mathrm{LaC}, 53 \%$ developed at least one gastrointestinal symptom after starting $\mathrm{LaC}$ treatment. Four patients required laxatives for constipation and one patient was treated with a proton pump inhibitor for epigastralgia during the study period. Although the $\mathrm{LaC}$ dose was reduced in two patients due to gastrointestinal side effects, none of the 30 patients discontinued $\mathrm{LaC}$ treatment during the study period.

\section{Effects of LaC treatment on nutritional status and adequacy of dialysis}

$\mathrm{LaC}$ treatment did not influence the nutritional status, as assessed by serum levels of urea nitrogen, serum creatinine, total cholesterol, triglyceride, albumin, and total protein. Furthermore, LaC treatment had no effect on the adequacy of dialysis, as assessed by total $\mathrm{Kt} / \mathrm{V}$ urea and total creatinine clearance (Table 5).

\section{Effects of LaC on serum Pi in patients with different serum $\mathrm{Ca}$ and serum Pi levels at baseline}

Serum Pi levels were approximately comparable between the high serum Pi group and low Pi group in the last of 24 weeks of treatment although the mean dose of $\mathrm{LaC}$ was higher in patients with higher serum $\mathrm{Pi}$ level at baseline (Fig. 3A, B). Similarly, serum Pi levels were approximately comparable between the high $\mathrm{Ca}$ group and low $\mathrm{Ca}$ group at 

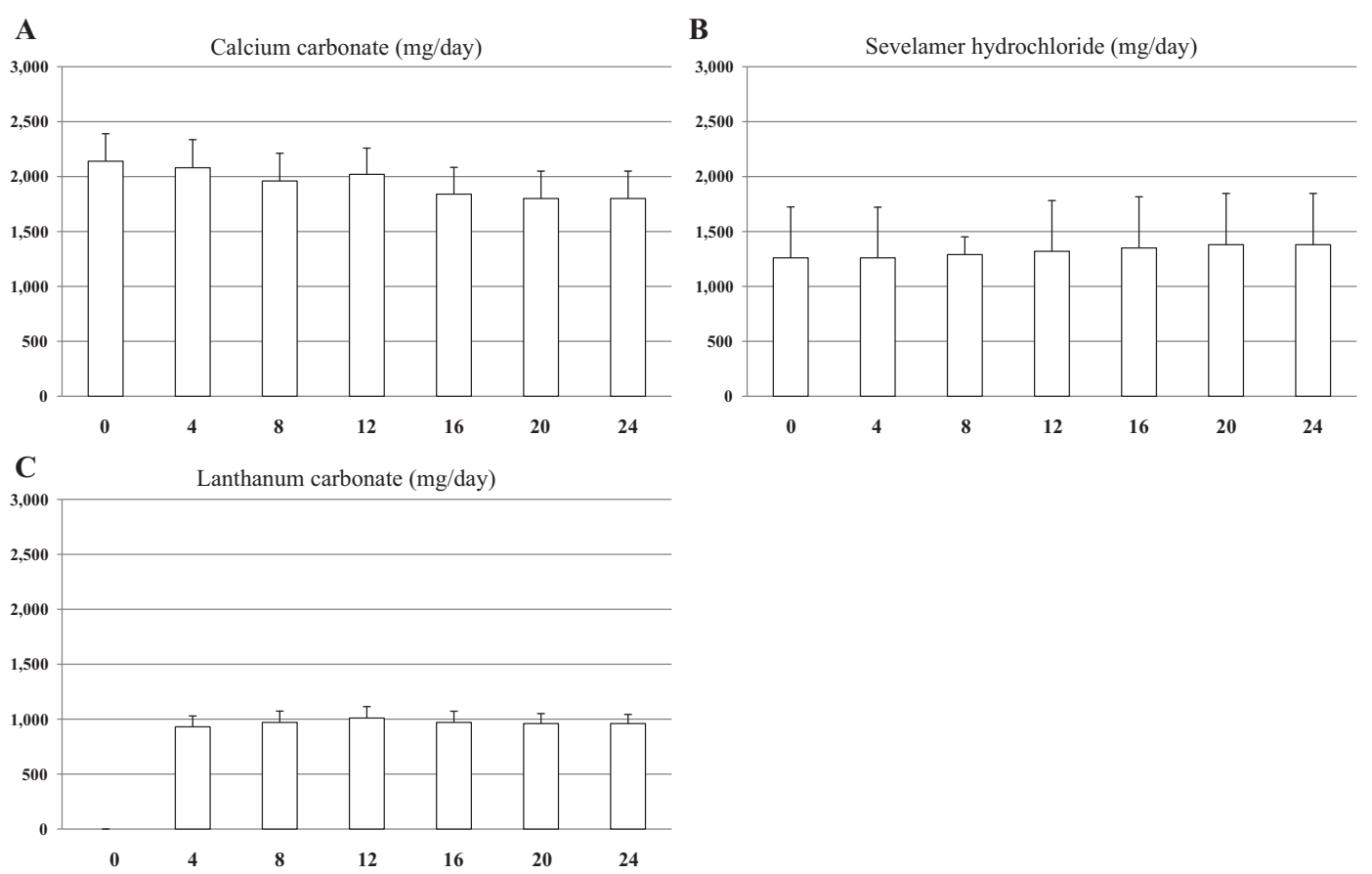

Figure 2. Serial changes in the daily dose of Pi binders. Daily doses of calcium carbonate (A), sevelamer hydrochloride (B), and lanthanum carbonate (C) are shown. Data shown in (A), (B), and (C) are mean \pm SEM. Data at each time point are compared with the baseline value (week 0 ) by Dunnett test. *p<0.05 versus serum phosphate $(\mathrm{Pi})$ at 0 week.

Table 4. Gastrointestinal Symptoms after Starting Lanthanum Carbonate $(n=30)$

\begin{tabular}{lr}
\hline & Number (\%) of patients \\
\hline Reflux, n (\%) & $11(37)$ \\
Abdominal pain, n (\%) & $10(33)$ \\
Indigestion, n (\%) & $7(23)$ \\
Diarrhea, n (\%) & $4(13)$ \\
Constipation, n (\%) & $6(20)$ \\
Any symptom, n (\%) & $16(53)$ \\
\hline Data are number (percentage) of patients.
\end{tabular}

almost the same dose of LaC (Fig. 3C, D).

\section{Univariate and multivariate analyses}

Univariate analysis showed that old age, high total creatinine clearance and short stature were significantly associated with response to $\mathrm{LaC}$ treatment (Table 6). On the other hand, sex, underlying kidney disease, PD vintage, body weight, body mass index, urine volume, total $\mathrm{Kt} / \mathrm{V}$ urea, dialysis fluid volume, albumin, corrected $\mathrm{Ca}, \mathrm{Pi}$, alkaline phosphatase, whole PTH, and the daily dose of Pi binders (Ca carbonate, sevelamer hydrochloride) did not significantly influence the response to $\mathrm{LaC}$ treatment. The above three independent variables were subsequently entered into multivariate logistic regression analysis. The results also showed that age, height and total creatinine clearance were independent and significant determinants of the response to $\mathrm{LaC}$ treatment.

Discussion

The present study demonstrated that low-dose LaC treatment for 24 weeks effectively reduced the serum Pi level in Japanese PD patients who were already treated with conventional Pi binders, and hence the same treatment increased the rate of achievement of JSDT guidelines for serum Pi. Previous studies have demonstrated the effectiveness of $\mathrm{LaC}$ in PD patients $(11,12)$. However, these studies only examined the short-term efficacy of $\mathrm{LaC}$ on serum Pi in PD patients. To our knowledge, there are no studies that have examined the effects of long-term treatment or the additive effects of $\mathrm{LaC}$ in PD patients who had already been treated with other Pi binders. Thus, the present study contributes to the management of hyperphosphatemia in PD patients in that it is the first to have examined the effectiveness and tolerability of low-dose $\mathrm{LaC}$ used in combination with other $\mathrm{Pi}$ binders for 24 weeks.

The effects of $\mathrm{LaC}$ on mineral metabolism other than serum Pi should be elucidated. In the present study, serum levels of $\mathrm{Ca}$, and PTH remained unchanged during the 24week $\mathrm{LaC}$ treatment, indicating that $\mathrm{LaC}$ treatment prevented the progression of SHPT. With regard to the effect of $\mathrm{LaC}$ treatment in dialysis patients, previous studies showed that 2-year $\mathrm{LaC}$ treatment improved bone metabolism and increased bone mineral density (14). In addition, experimental studies have demonstrated that long-term $\mathrm{LaC}$ treatment inhibited SHPT, renal osteodystrophy and vascular calcification $(15,16)$. These results indicate that $\mathrm{LaC}$ can potentially 
Table 5. Clinical and Biochemical Parameters Related to Nutritional Status and Dialysis Adequacy before and after Lanthanum Carbonate Treatment in 30 Patients

\begin{tabular}{lrrr}
\hline & $\begin{array}{c}\text { Pre-treatment } \\
\text { (week 0) }\end{array}$ & $\begin{array}{c}\text { Post-treatment } \\
\text { (week 24) }\end{array}$ & p value* \\
\hline Blood urea nitrogen, mg/dL & $61.8 \pm 12.7$ & $64.5 \pm 11.6$ & 0.458 \\
Serum creatinine, mg/dL & $12.1 \pm 2.9$ & $12.3 \pm 2.7$ & 0.769 \\
Total protein, g/dL & $6.3 \pm 0.6$ & $6.2 \pm 0.7$ & 0.873 \\
Albumin, g/dL & $3.5 \pm 0.5$ & $3.4 \pm 0.4$ & 0.895 \\
Total cholesterol, mg/dL & $144 \pm 109$ & $189 \pm 44$ & 0.074 \\
Triglyceride, mg/dL & $185 \pm 48$ & $155 \pm 75$ & 0.102 \\
Body weight, kg & $62.7 \pm 11.3$ & $62.8 \pm 11.7$ & 0.659 \\
nPCR, g/kg/day & $0.96 \pm 0.22$ & $0.92 \pm 0.17$ & 0.890 \\
Dialysis volume, L/day & $8.00 \pm 2.17$ & $8.09 \pm 2.26$ & 0.602 \\
Total Kt/V urea & $1.81 \pm 0.57$ & $1.71 \pm 0.37$ & 0.366 \\
Total CCr, L/week & $59.1 \pm 20.1$ & $53.6 \pm 15.7$ & 0.222 \\
\hline Data are mean \pm SD. & \multicolumn{3}{|}{} \\
*by paired $t$-test, nPCR: normalized protein catabolic rate, Kt/V urea: urea clearance, \\
CCr: creatinine clearance & & &
\end{tabular}

Table 6. Univariate and Multivariate Adjusted Odds Ratios for Response to Lanthanum Carbonate Therapy $(n=30)$

\begin{tabular}{lcccc}
\hline \multirow{2}{*}{ Variable } & \multicolumn{2}{c}{ Univariate } & \multicolumn{2}{c}{ Multivariate } \\
\cline { 2 - 5 } & OR $(95 \%$ CI $)$ & p value & OR (95\% CI) & p value \\
\hline Height, per 0.01 meter & $0.869(0.807-0.932)$ & 0.025 & $0.818(0.632-0.969)$ & 0.018 \\
Age, per 1 year & $1.174(1.107-1.237)$ & 0.017 & $1.189(1.023-1.529)$ & 0.020 \\
Total CCr, per 1 L/week & $1.072(1.039-1.105)$ & 0.012 & $1.131(1.024-1.324)$ & 0.010 \\
\hline Odds ratio is for "responders". & & \\
A p value less than 0.05 is considered statistically significant. & \\
CCr: creatinine clearance, OR: odds ratio, CI: confidence interval &
\end{tabular}

prevent the progression of mineral and bone disorders through inhibition of Pi overload. Because Pi overload is located upstream of all disorders of bone and mineral metabolism in patients with renal failure (17), its control by $\mathrm{Pi}$ binder is probably the most important treatment strategy.

Among the several factors that enhance patient adherence to Pi binder therapy, gastrointestinal side effects and the dosage of Pi binders are the most important (18). Clinical data indicate that serum Pi can be reduced by all Pi binders irrespective of their types, provided they are administered in large doses. However, the incidence and severity of gastrointestinal symptoms are known to increase with the use of higher dosage (19). Thus, Pi binders that can reduce serum Pi with the smallest dose are desirable and preferred. Adherence to $\mathrm{Pi}$ binder therapy was recently reported to be the best with $\mathrm{Ca}$ carbonate, followed by $\mathrm{LaC}$ and sevelamer hydrochloride (20). In that study, patient preference was mostly related to gastrointestinal side effects and the drug dosage. In the present study, the gastrointestinal side effects were acceptable and none of the patients discontinued $\mathrm{LaC}$ therapy. One reason for the high $\mathrm{LaC}$ tolerability might be the relatively low dose of $\mathrm{LaC}$ used in the treatment $(960$ $\mathrm{mg}$ /day). In fact, one study reported that $\mathrm{LaC}$ can effectively reduce serum $\mathrm{Pi}$ when used at low dose compared with other Pi binders, leading to low incidence of gastrointestinal side effects per serum Pi reduction (21). From the point of $\mathrm{LaC}$ dosage and related side effects, the present study con- firmed the potential tolerability of low dose $\mathrm{LaC}$ treatment, leading to better clinical outcome in PD patients.

Maintenance of a good nutritional status is also important in the management of PD patients since recent clinical data have shown that malnutrition is closely associated with high mortality in PD patients $(22,23)$. On the other hand, the use of Pi binders is often accompanied by gastrointestinal symptoms, occasionally leading to appetite loss and possible malnutrition. In the present study, LaC treatment did not influence the nutritional status, as assessed by various biochemical parameters, although more than half of the patients experienced at least one type of LaC-related gastrointestinal side effect. These results indicate that $\mathrm{LaC}$ treatment within the dose used in the present study is efficacious in controlling serum Pi level without affecting the nutritional status of PD patients.

Little is known about the factors that influence serum $\mathrm{Pi}$ reduction with the use of $\mathrm{Pi}$ binders. In the present study, low dose of $\mathrm{LaC}$ added on other Pi binders effectively reduced serum Pi level independent of the baseline serum Pi and $\mathrm{Ca}$ level. However, multivariate analysis revealed that a greater reduction in serum Pi level was associated with older age, low stature and high total creatinine clearance at baseline. These results can be better understood when we consider the following in-out balance model regarding Pi. In PD patients, serum Pi level is determined by: 1) Pi intake by meal, 2) distribution volume of $\mathrm{Pi}$ in the body, 3) $\mathrm{Pi}$ ex- 

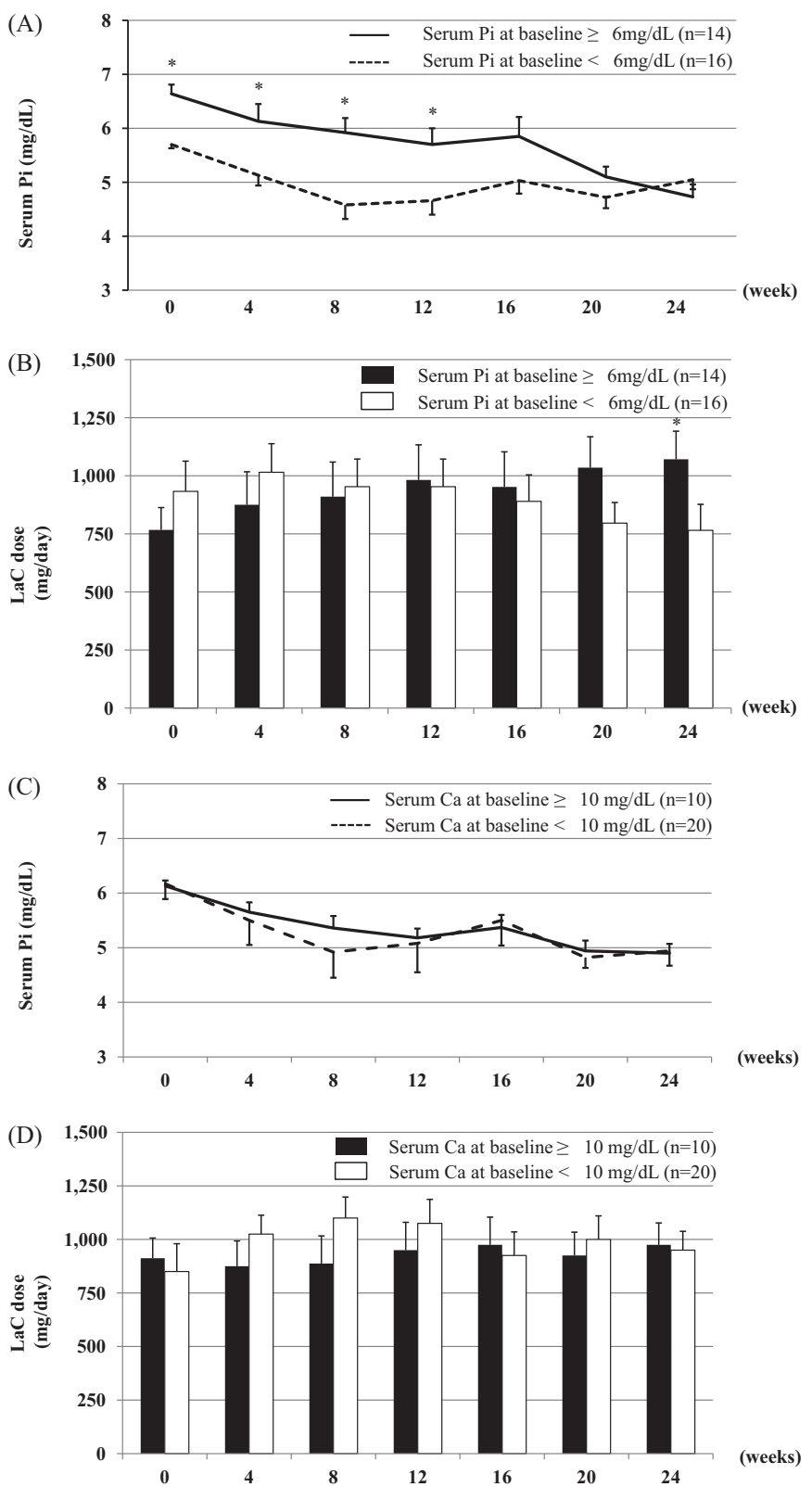

Figure 3. Effects of $\mathrm{LaC}$ on serum $\mathrm{Pi}$ reduction in patients with different serum $\mathrm{Ca}$ and Pi control levels at baseline. Serial changes in serum phosphate $(\mathrm{Pi})$ in the two groups divided by the basal level of serum $\mathrm{Pi}$ and calcium $(\mathrm{Ca})$, respectively $(\mathrm{A}, \mathrm{C})$ are shown. Serial changes in the dose of $\mathrm{LaC}$ in both groups $(B, D)$. Data shown in $(A)$ and $(C)$ are mean \pm SEM. Data between two groups at each time point were compared by un-paired t-test. * $\mathbf{p}<0.05$ versus serum $\mathrm{Pi}$ at baseline $<6$ mg/dL. LaC: lanthanum carbonate

change between bone and blood and 4) renal excretion of Pi and removal through PD dialysate (24). Thus, smaller Pi intake, large distribution volume and higher $\mathrm{Pi}$ clearance through the kidney and PD dialysate should lower the serum Pi level. With regard to the factors identified in the present study, elderly patients take less $\mathrm{Pi}$, and low stature is related to small distribution volume of $\mathrm{Pi}$, and high total creatinine clearance is thought to be closely related to greater Pi excretion.
The present study has several limitations. First, the present study was a retrospective study with a small sample size and without controls. Second, we did not determine whether independent factors related to $\mathrm{Pi}$ reduction identified by multivariate analysis might be also true in the different $\mathrm{Pi}$ binders such as $\mathrm{Ca}$ carbonate or sevelamer hydrochloride. Third, some patients in the present study started to receive LaC because they could not use other Pi binders for hypercalcemia or gastrointestinal side effects; the present study could have some inclusion bias. Accordingly, the effects of $\mathrm{LaC}$ could be different if used in another PD population. Thus, further large scale studies with controls are necessary to determine the additive effects of low-dose LaC in PD patients.

In conclusion, the combination therapy of low-dose LaC with other Pi binders effectively reduced serum Pi level in Japanese PD patients and improved the rate of achievement of Pi target recommended by the JSDT guidelines with tolerable gastrointestinal side effects. The addition of low-dose $\mathrm{LaC}$ could be a useful therapeutic option in PD patients with persistent hyperphosphatemia already treated with other Pi binders.

The authors state that they have no Conflict of Interest (COI).

\section{Acknowledgement}

We thank Dr. F. G. Issa (Word-Medex) for editing our manuscript.

\section{References}

1. Lowrie EG, Lew NL. Death risk in hemodialysis patients: the predictive value of commonly measured variables and an evaluation of death rate differences between facilities. Am J Kidney Dis 15: 458-482, 1990.

2. Delmez JA, Slatopolsky E. Hyperphosphatemia: its consequence and treatment in patients with chronic renal disease. Am J Kidney Dis 19: 303-317, 1999.

3. Block GA, Klassen PS, Lazarus JM, Ofsthun N, Lowrie EG, Chertow GM. Mineral metabolism, mortality, and morbidity in maintenance hemodialysis. J Am Soc Nephrol 15: 2208-2218, 2004.

4. Noordzij M, Korevaar JC, Boeschoten EW, Dekker FW, Bos WJ, Krediet RT. Netherlands Cooperative Study on the Adequacy of Dialysis (NECOSAD) Study Group. The Kidney Disease Outcome and Quality Initiative (K/DOQI) guideline for bone metabolism and disease in CKD: association with mortality in dialysis patients. Am J Kidney Dis 23: 925-932, 2005.

5. Noordzij M, Korevaar JC, Bos WJ, et al. Mineral metabolism and cardiovascular morbidity and mortality risk: peritoneal dialysis patients compared with haemodialysis patients. Nephrol Dial Transplant 21: 2513-2520, 2006.

6. Wang AY, Woo J, Sea MM, Lau MC, Lui SF, Li PK. Hyperphosphatemia in Chinese peritoneal dialysis patients with or without residual kidney function; what are the implications? Am J Kidney Dis 43: 712-720, 2004.

7. Gokal R. The preferred phosphate binder in dialysis patients. Perit Dial Int 19: 405-408, 1999.

8. Hutchinson AJ. Oral phosphate binders. Kidney Int 75: 906-914, 2009.

9. Drueke T. Lanthanum carbonate as a first-line phosphate binder: 
the "cons". Semin Dial 20: 329-332, 2007.

10. Shigematsu T, and the Lanthanum Carbonate Group. Multicenter prospective randomized double-blind comparative study between lanthanum carbonate and calcium carbonate as phosphate binders in Japanese hemodialysis patients with hyperphosphatemia. Clin Nephrol 70: 404-410, 2008.

11. Al-Baaj FA, Speake M, Hutchison AJ. Control of serum phosphate by oral lanthanum carbonate in patients undergoing haemodialysis and continuous ambulatory peritoneal dialysis in a short-term, placebo-controlled study. Nephrol Dial Transplant 20: 775-782, 2005.

12. Kawanishi $H$, Ishida $M$, Ishizaki $M$, et al. Lanthanum carbonate treatment of patients with hyperphosphatemia undergoing CAPD. Perit Dial Int 28: 673-675, 2008.

13. Kazama JJ. Japanese Society of Dialysis Therapy treatment guidelines for secondary hyperparathyroidism. Ther Apher Dial 11 (Suppl 1): S44-S47, 2007.

14. Malluche HH, Siami GA, Swanepoel C, et al. Improvement in renal osteodystrophy in patients treated with lanthanum carbonate for two years. Clin Nephrol 70: 284-295, 2008.

15. Ben-Dov IZ, Pappo O, Sklair-Levy M, et al. Lanthanum carbonate decreases PTH gene expression with no hepatotoxicity in uraemic rats. Nephrol Dial Transplant 22: 362-368, 2007.

16. Neven E, Dams G, Postnov A, et al. Adequate phosphate binding with lanthanum carbonate attenuates arterial calcification in chronic renal failure rats. Nephrol Dial Transplant 24: 1790-1799,
2009.

17. Coladonato JA. Control of hyperphosphatemia among patients with ESRD. J Am Soc Nephrol 16 (Suppl 2): S107-S114, 2005.

18. Arenas MD, Malek T, Alvarez-Ude F, Cil MT, Moledous A, ReigFerrer A. Phosphorus binders: preferences of patients on haemodialysis and its impact on treatment compliance and phosphorus control. Nefrologia 30: 522-530, 2010.

19. Curran MP, Robinson DM. Lanthanum carbonate. A review of its use in lowering serum phosphate in patients with end-stage renal disease. Drugs 69: 2329-2349, 2009.

20. Daugirdas JT, Finn WF, Emmett M, et al. The phosphate binder equivalent dose. Semin Dial 24: 41-49, 2011.

21. Hutchison AJ, Laville M; SPD405-313 Lanthanum Study Group. Switching to lanthanum carbonate monotherapy provides effective phosphate control with a low tablet burden. Nephrol Dial Transplant 23: 3677-3684, 2008.

22. Ho LC, Wang HH, Chiang CK, Hung KY, Wu KD. Malnutritioninflammation score independently determined cardiovascular and infection risk in peritoneal dialysis patients. Blood Purif 30: 1624, 2010.

23. Chung SH, Lindholm B, Lee HB. Influence of nutritional status on continuous ambulatory peritoneal dialysis patient survival. Perit Dial Int 20: 19-26, 2000.

24. Hruska KA, Mathew S, Lund R, et al. Hyperphosphatemia of chronic kidney disease. Kidney Int 74: 148-157, 2008.

(C) 2012 The Japanese Society of Internal Medicine http://www.naika.or.jp/imonline/index.html 